\title{
Effect of the secondary substances from wheat on the growth and digestive physiology of cotton bollworm Helicoverpa armigera (Lepidoptera: Noctuidae)
}

\author{
Yu WANG, QING-NIAN CAI*, QING-WEN ZHANG* and YING HAN \\ Department of Entomology, China Agricultural University, Beijing 100094, P. R. China; e-mail caign@cau.edu.cn; \\ zhangqingwen@z63.net
}

Key words. Pyrocatechol, ferulic acid, gramine, nutritional index, cotton bollworm, Helicoverpa armigera

\begin{abstract}
Three secondary compounds, pyrocatechol, gramine and ferulic acid from wheat were separately incorporated into artificial diets and fed to cotton bollworm Helicoverpa armigera (Hübner) larvae to determine their effects on larval and pupal weights and the nutritional indices of the larvae. The results show that these three secondary compounds can decrease the mean larval and pupal weights of cotton bollworm, with the mean larvae weights differing significantly between treatments. Mean pupal weight was only significantly reduced by ferulic acid and gramine, but not pyrocatechol. There were significant correlations between mean larval weight and concentration of the three secondary compounds tested, and between mean pupal weight and concentration of ferulic acid and gramine. The three secondary compounds tested affected the nutritional indices of cotton bollworm larvae differently. Compared with the control, ferulic acid and gramine significantly decreased RGR (the relative growth rate), AD (approximate digestibility) and ECD (conversion efficiency) of cotton bollworm larvae, and pyrocatechol only reduced ECD. All three indices were the lowest for cotton bollworm larvae fed on the diet with gramine $(0.0984 \pm 0.0114 \mathrm{~g} / \mathrm{g} / \mathrm{day}, 14.2670 \pm 1.1541 \%$ and 31.1337 $\pm 1.1213 \%)$.
\end{abstract}

\section{INTRODUCTION}

Cotton bollworm is one of the most important pest insects in many countries of world and is responsible for destroying a lot of crop plants. In 1990s, the cotton bollworm caused serious damage around the world, which resulted as a huge reduction in cotton production. In north China $1^{\text {st }}$ generation cotton bollworm larvae mainly injure winter wheat in the late stage growth with $90 \%$ of the eggs of the $1^{\text {st }}$ generation oviposited on wheat ears (He et al., 1996; Xia et al., 1997). The larvae mainly feed on wheat ears. One larva can destroy approximately 47.7 grains (Wang et al., 1997b). Thus the cotton bollworm infestations of wheat are an important source of pests which infest cotton and other crops after the wheat is harvested (He et al., 1996; Wang et al., 1997b).

Host plant resistance has been an important component of the integrated management of cotton bollworm. Secondary plant substances play an important role in the resistance of cotton to cotton bollworm. Some studies using different tissues of cotton plant and diets-containing secondary compounds (Wang, 1997; Wang et al., 1997a) indicate that gossypol and tannic acid in cotton determine the relative growth rate and efficiency of conversion of ingested food by Helicoverpa armigera (Hbn). In wheat secondary substances, such as phenolics, indole alkaloids and non-protein amino acids, are important in the resistance to insects (Ciepiela \& Sempruch, 1999). Wheat with high resistance to aphids contains high levels of total phenolics and tannin (Chen et al., 1997). Indole alkaloids are widely present in Gramineae. The indole alkaloid (i.e. gramine) can be toxic to Schizaphis graminum, Rhopalosiphum padi and Sitobion avenae (Zuñiga et al., 1985). Compared to total phenolics, the indole alkaloid content is highly correlated with the number of $S$. avenae infesting wheat ears (Cai et al., 2003). The levels of secondary substances in different plant tissues vary and may change as plants grow and develop (Thackray et al., 1990;

\footnotetext{
* Corresponding authors.
}

Kazemi \& van Emden, 1992; Nicol et al., 1992; Cai et al., 2004).

In addition, the secondary compounds of gramineous plants significantly affect the growth and development of Lepidoptera (Manuwoto \& Scriber, 1985). Ortego et al. (1998) report that in long-term feeding assays DIMBOA can reduce the relative growth rate and the efficiency of conversing ingested food by the salk corn borer Ostrinia furnacalis (Guenee) without affecting the relative consumption rate. Therefore, the objective of this paper was to determine the effect of three secondary compounds from wheat on the growth, development and nutrition of cotton bollworm larvae, and to compare the effects of these three compounds.

\section{MATERIAL AND METHODS}

\section{Cotton bollworm culture}

Cotton bollworm larvae were reared on artificial diets at 26 $27^{\circ}, 70 \sim 80 \% \mathrm{RH}$ and $14 \mathrm{~L}: 10 \mathrm{D}$ photoperiod. The artificial diet was a modified version of that developed by Bot (1966). The cotton bollworm culture was maintained on this diet for 10 generations.

\section{Wheat secondary compounds}

Pyrocatechol (analytically pure), trans-ferulic acid (chemically pure) and gramine (chemically pure) were obtained from the Beijing chemical company (China), Shanghai chemical reagent company (China) and Kingsley and Keith (Chemicals) Ltd (UK), respectively.

\section{Growth and development of cotton bollworm}

Pyrocatechol and ferulic acid were separately dissolved in distilled water and in $70 \%$ ethanol and then incorporated into the artificial diet of the cotton bollworm at a concentration of 0 , $0.12,0.33,0.46,0.78$ or $1.57 \mathrm{mg} / \mathrm{g}$ and less than $1 \%$ ethanol. Gramine was firstly dissolved in $100 \%$ ethanol, then distilled water was added to give a final concentration of ethanol of $70 \%$, 

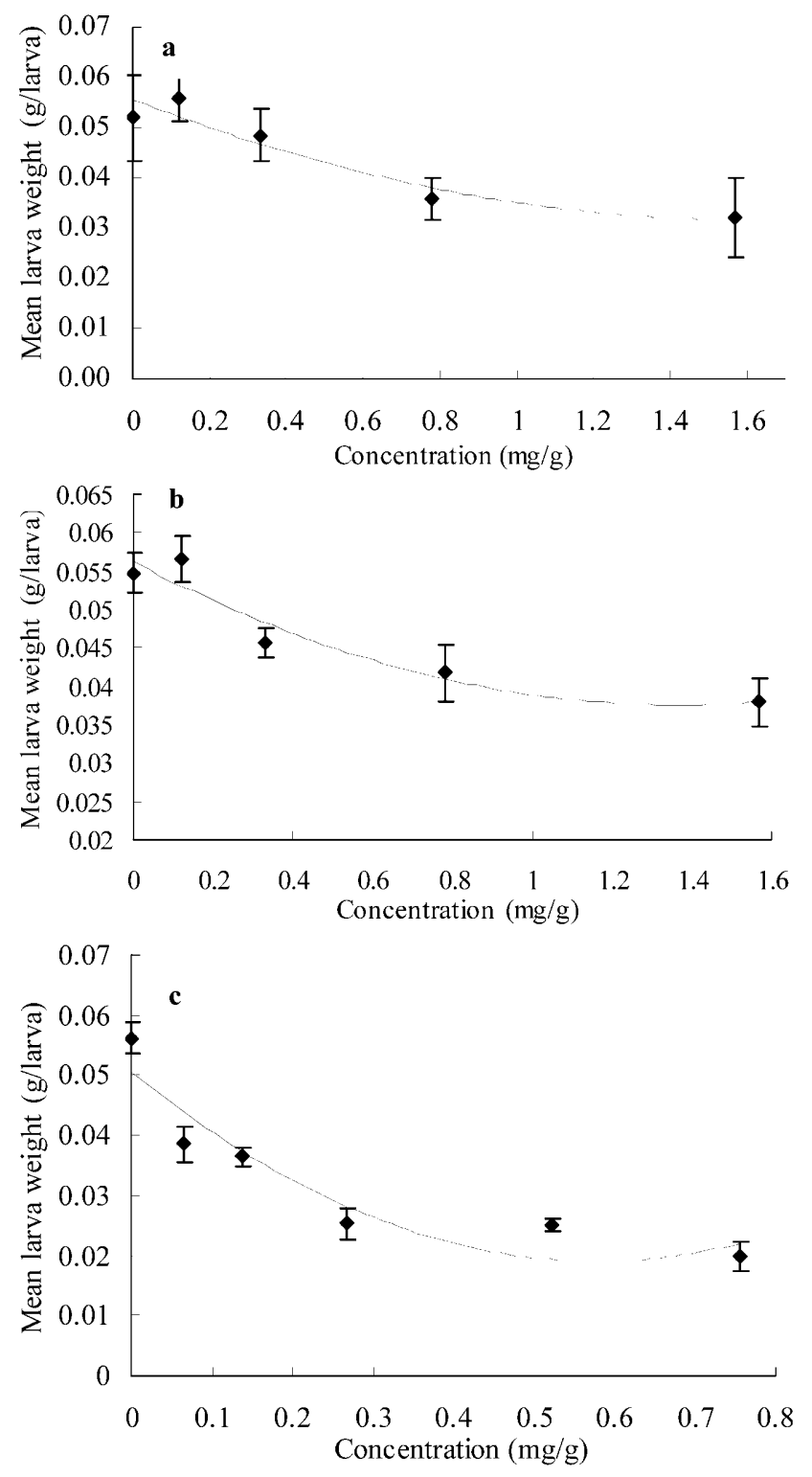

Fig. 1. Effect of different concentrations of pyrocatechol (a), ferulic acid (b) and gramine (a) on the mean larval weight of cotton bollworm.

which was then mixed with the artificial diet to give concentrations of $0,0.07,0.14,0.27,0.53$ or $0.78 \mathrm{mg} / \mathrm{g}$ and less than $1 \%$ ethanol. The ethanol content of the ferulic acid and gramine controls were the same as in the treatments (less than $1 \%$ ethanol). Ten newly hatched larvae of the cotton bollworm were separately reared on artificial diet containing secondary compounds in glass tubes $(10 \mathrm{~mm} \varnothing)$ at $26 \sim 27^{\circ} \mathrm{C}, 70 \sim 80 \% \mathrm{RH}$ and 14L : 10D photoperiod. This was repeated three times for each treatment. After 10 days, the larvae were weighed on a Poton electronic balance (Germany) and then transferred to the original diet until they pupated when they were weighed again.

\section{Physiological test on larval digestion}

Following the method described byWaldbauer (1968) and Wang (1997), gramine, pyrocatechol, and ferulic acid were dissolved in $70 \%$ ethanol and incorporated into the artificial diet of the cotton bollworm. The concentration of the three secondary compounds in the diet was each $0.3 \%$ by weight. Forty cotton bollworm larvae reared on the normal diet for 8 days were
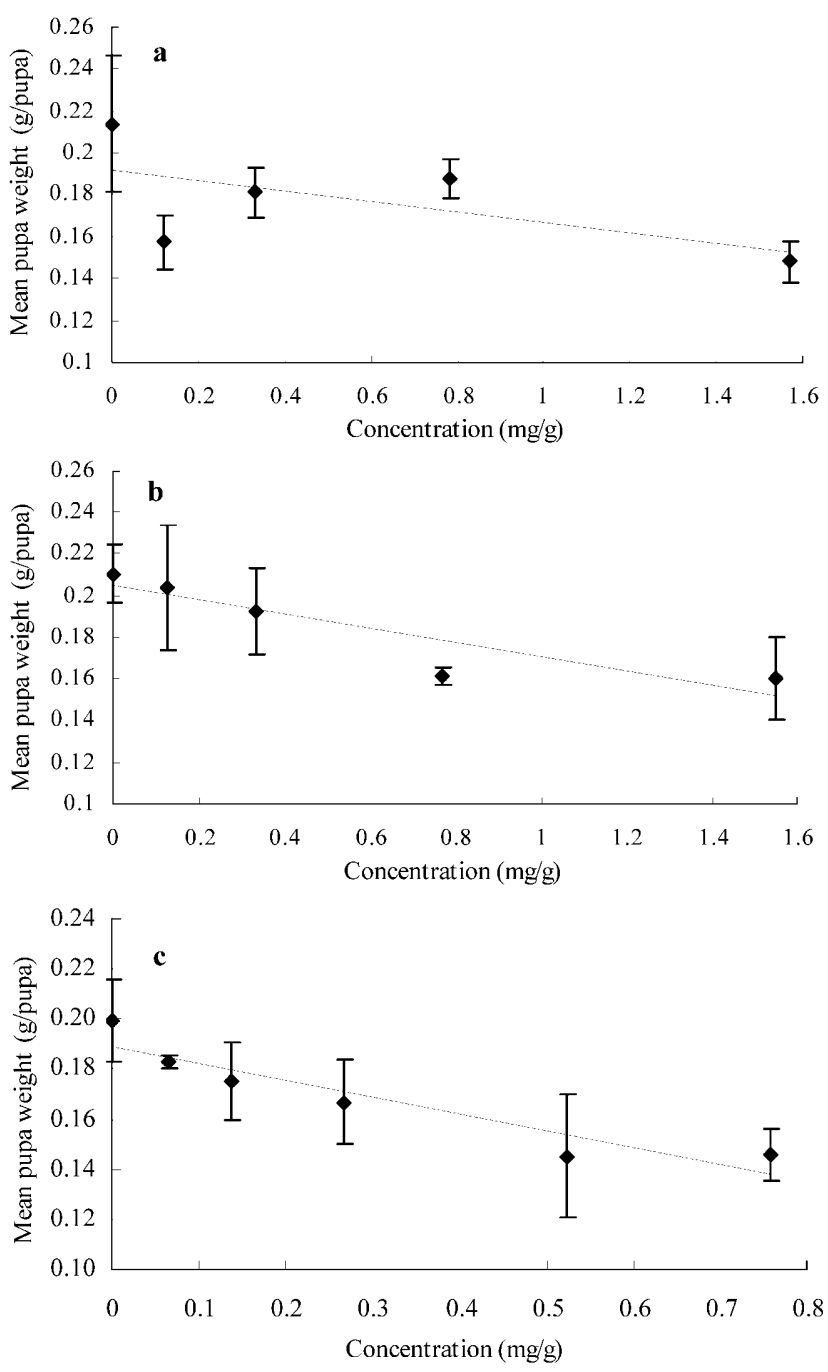

Fig. 2. Effects of different concentrations of pyrocatechol (a), ferulic acid (b) and gramine (c) on the mean pupal weight of cotton bollworm.

weighed, then starved for $10 \mathrm{~h}$ before dividing into four groups of ten larvae. These four groups of larvae were each reared on one of the three diets containing wheat secondary compounds or the control diet in a Petri dish $(9 \mathrm{~cm} \varnothing)$ at $26 \sim 27^{\circ} \mathrm{C}, 70 \sim 80 \%$ $\mathrm{RH}$ and $14 \mathrm{~L}: 10 \mathrm{D}$ photoperiod, one larva per petri dish and each treatment was replicated ten times. After $72 \mathrm{~h}$, the larvae were weighed and immediately frozen in an icebox, subsequently the frozen larvae, faeces and remaining diet were dried at $50^{\circ} \mathrm{C}$ for $24 \mathrm{~h}$, then adjust temperature to $100^{\circ} \mathrm{C}$ to dry for 24 $\mathrm{h}$. The dry larvae, faeces and remaining diet in each treatment were weighed. Using the dry weight of the diets before the experiment (A), dry weight of the diets after the experiment (B), dry weight of larvae before the experiment $(\mathrm{C})$, dry weight of larvae after the experiment (D) and dry weight of faeces (E), the relative growth rate (RGR), approximate digestibility (AD) and conversion efficiency of digestion (ECD) were calculated using Waldbauer's formulae (Waldbauer, 1968):

$$
\begin{gathered}
\mathrm{RGR}=(\mathrm{D}-\mathrm{C}) /[(\mathrm{C}+\mathrm{D}) / 2] \times 3 \\
\mathrm{AD}=(\mathrm{A}-\mathrm{B}-\mathrm{E}) /(\mathrm{A}-\mathrm{B}) \times 100 \\
\mathrm{ECD}=(\mathrm{D}-\mathrm{C}) /(\mathrm{A}-\mathrm{B}-\mathrm{E}) \times 100
\end{gathered}
$$


TABLE 1. The nutritional indices of larvae of Helicoverpa armigera fed on diets containing one of three wheat secondary compounds $(\mathrm{n}=10)$.

\begin{tabular}{lccc}
\hline Treatment & $\begin{array}{c}\text { Relative growth ratio } \\
\text { RGR }(\mathrm{g} / \mathrm{g} / \mathrm{day}) \pm \mathrm{SE}\end{array}$ & $\begin{array}{c}\text { Approximate digestibility } \\
\text { AD }(\%) \pm \mathrm{SE}\end{array}$ & $\begin{array}{c}\text { Conversion efficiency } \\
\text { ECD }(\%) \pm \text { SE }\end{array}$ \\
\hline Control & $0.1149 \pm 0.0110 \mathrm{a}$ & $21.3721 \pm 1.2590 \mathrm{a}$ & $41.2487 \pm 1.1858 \mathrm{a}$ \\
Pyrocatechol & $0.1158 \pm 0.0128 \mathrm{a}$ & $20.1856 \pm 1.2992 \mathrm{a}$ & $35.1204 \pm 1.2047 \mathrm{~b}$ \\
Ferulic acid & $0.1003 \pm 0.0130 \mathrm{~b}$ & $15.4555 \pm 1.2165 \mathrm{~b}$ & $34.8220 \pm 1.1703 \mathrm{~b}$ \\
Gramine & $0.0984 \pm 0.0114 \mathrm{~b}$ & $14.2670 \pm 1.1541 \mathrm{~b}$ & $31.1337 \pm 1.1213 \mathrm{~b}$ \\
\hline
\end{tabular}

RGR - Relative growth ratio $(\mathrm{df}=3,36, \mathrm{~F}=5.884, \mathrm{P}<0.05), \mathrm{AD}-$ Approximate digestibility $(\mathrm{df}=3,36, \mathrm{~F}=8.668, \mathrm{P}<0.05)$ and $\mathrm{ECD}-$ Conversion efficiency $(\mathrm{df}=3,36, \mathrm{~F}=5.279, \mathrm{P}<0.05)$. Numbers followed by the same letter are not significantly different (Duncan ANOVA test).

\section{Data analysis}

Analysis of variance of the data was done using SPSS (version 12.0) and regression analysis of mean larval and pupal weights using Microsoft Excel 2000 software.

\section{RESULTS}

\section{Effect of pyrocatechol, gramine and ferulic acid on larval weight}

The mean larval weight of cotton bollworm fed the diet with different concentration of pyrocatechol was lower than the control at $0.33,0.78$ and $1.57 \mathrm{mg} / \mathrm{g}$ concentrations, but higher at the $0.12 \mathrm{mg} / \mathrm{g}$ concentration (Fig. 1a). The mean weight of larvae fed different concentrations of pyrocatechol differ significantly $(\mathrm{df}=1,4, \mathrm{~F}=18.7689, \mathrm{P}<0.05)$, there is negative correlation between mean larval weight and pyrocatechol concentration $(\mathrm{df}$ $=3,3 ; \mathrm{R}=-0.956$ ).

Ferulic acid can influence the growth and development of cotton bollworm larvae. With increase in concentration of ferulic acid, mean larval weight decreased except at the concentration of $0.12 \mathrm{mg} / \mathrm{g}$ (Fig. 1b) and the mean larval weight differed significantly when they were fed the various concentrations of ferulic acid $(\mathrm{df}=1,4, \mathrm{~F}=12.5105, \mathrm{P}<0.05)$. Mean larval weight was negatively correlated with the concentrations of ferulic acid $(\mathrm{df}=3,3 ; \mathrm{R}=-0.957)$.

Gramine significantly reduced the growth of cotton bollworm larvae (Fig. 1c). The mean weight of larvae fed on artificial diet with a high gramine concentration $(0.78 \mathrm{mg} / \mathrm{g})$ was $36.8 \%$ less than when fed on artificial diet with a low gramine concentration $(0.07 \mathrm{mg} / \mathrm{g})$. That is, the mean weight of larvae fed on the diets with various gramine concentrations differed significantly $(\mathrm{df}=1,5, \mathrm{~F}=9.7725, \mathrm{P}<0.05)$. The mean weight of larvae of cotton bollworm was negatively correlated with the concentration of gramine $(\mathrm{df}=4,3 ; \mathrm{R}=-0.936)$.

\section{Effect of pyrocatechol, gramine and ferulic acid on pupal weight}

Fig. 2a indicates that pyrocatechol influences the mean pupal weight of cotton bollworm. Although the mean pupal weight in all treatments was lower than in the control, there was no significant difference in the mean pupal weights in the different treatments $(\mathrm{df}=1,4, \mathrm{~F}=1.6571, \mathrm{P}>0.05)$. There is also no correlation between mean pupal weight and pyrocatechol concentration $(\mathrm{df}=3,2 ; \mathrm{r}=0.608)$.

Both ferulic acid and gramine can significantly decrease the mean pupal weight of cotton bollworm, the higher the concentration of ferulic acid and gramine, the lower the mean pupal weight (Fig. 2b, c). The mean pupal weight when reared on diet with different concentrations of ferulic acid or gramine differed significantly $\left(\mathrm{df}_{\mathrm{FA}}=1,4, \mathrm{~F}=27.0989, \mathrm{P}<0.05 ; \mathrm{df}_{\mathrm{GR}}=1,5, \mathrm{~F}=\right.$ $13.4478, \mathrm{P}<0.05$ ). Moreover, mean pupal weight was highly significantly correlated with the concentration of ferulic acid and gramine $\mathrm{df}=3,2 ; \mathrm{r}_{\mathrm{FA}}=-0.988 ; \mathrm{df}=4,2 ; \mathrm{r}_{\mathrm{GR}}=-0.991$ ).

\section{Effect of pyrocatechol, gramine and ferulic acid on nutri- tional indices of larvae}

Results in Table 1 indicate that the chemicals tested had different effects on the nutritional indices of cotton bollworm larvae. Although diet containing pyrocatechol significantly reduced the ECD, it did not affect the RGR and AD of the larvae, whereas ferulic acid and gramine both significantly reduced RGR, AD and ECD, especially gramine. All three compounds significantly reduced the ECD of cotton bollworm larvae.

\section{CONCLUSION AND DISCUSSION}

Three secondary compounds found in wheat can affect the growth of cotton bollworm larvae. When fed diets containing the three compounds, their weight increase variance was significantly or highly significantly correlated to their concentration of the secondary compounds in the diet. These results imply that the growth and development of cotton bollworm larvae is affected by phenolic (pyrocatechol and ferulic acid) and alkaloid (gramine) compounds from plants. Previous studies indicate that plant secondary compounds from cotton can adversely affect the growth and development of cotton bollworm. Homchan et al. (1985) reported that the larvae of Helicoverpa armigera fed the potentially resistant cotton lines containing gossypol were smaller. When the concentration of gossypol acetic acid in a diet is $0.3 \%$ and above, none of the larvae reach the pupal stage (Suprada, 1989). In addition, flavonoids of cotton buds incorporated into laboratory diets are moderately toxic, and decreased larval survival was observed in Heliothis virescens (F.) (Hedin et al., 1992). Our results are consistent with these studies on the secondary compounds of cotton.

The mean pupal weights of cotton bollworm fed on diets containing one of three secondary compounds were smaller. However, the mean pupal weights of cotton bollworm were only significantly correlated with the concentration of ferulic acid or gramine in the diet, not pyrocatechol. Suprada (1989) reports that gossypol acetic acid, rutin and quercetin in diets did not affect the pupal weight of cotton bollworm. This may be because these secondary compounds from different plants have a different effect on cotton bollworm.

The nutritional indices (RGR, AD and ECD) of cotton bollworm were significantly affected by ferulic acid and gramine, but pyrocatechol only affected ECD. It is possible that secondary compounds affect the activities of digestive enzymes. For example, the gossypol from cotton can inhibit proteinase activity and lipid deoxidate in Spodoptera littoralis (Meisner et al., 1987), tannic acid can combine with digestive enzymes and decrease the digestion of food (Feeny, 1976), both gossypol and tannic acid can influence proteinase activity in the midgut of cotton bollworm (Wang, 1997).

It remains to be shown whether the three secondary compounds tested inhibit digestive enzymes and so decrease the nutritional indices of cotton bollworm larva. The effect of sec- 
ondary compounds should be studied in detail to understand the mechanism of their action. Then the attempts might be undertaken to breed crop varieties with increased level of allelochemicals that would be resistant to pests.

ACKNOWLEDGEMENTS. This work was financially supported by the Initiation Project of Scientific Research, China Agricultural University, and "973" national key research program (2006CB100204), China Ministry of Science and Technology. We thank Y. Huang, Sydney University, Australia, for commenting on our manuscript.

\section{REFERENCES}

Вот J. 1966: Rearing Heliothis armigera Hubn. and Prodenia litura F. on an artificial diet. S. Afr. Agric. Sci. 9: 538-539.

Cabrera H.M., Munoz O., Zuniga G.E., Corcuera L.J. \& Argandona V.H. 1995: Changes in ferulic acid and lipid content in aphid-infested barley. Phytochemistry 39: 1023-1026.

Cai Q.N., Zhang Q.W., Gao X.W., Wang Y. \& Cheo M. 2003 Effects of the secondary substances on wheat resistance to Sitobion avenae (F.). Sci. Agric. Sin. 36: 910-915.

CAI Q.N., Wang Y., Zhang Q.W. \& Cheo M. 2004: Dynamics of indole alkaloids in wheat varieties with various resistance to the wheat aphid, Sitobion avenae. Chin. J. Appl. Ecol. 15: 537-539.

Chen J.L., Sun J.R., Ding H.J., Ni H.X. \& Li X.F. 1997: The resistance types and bio-chemical mechanism of major aphid resistance wheat. Acta Entomol. Sin. (Suppl.) 40: 190-195.

Ciepiela A.P. \& Sempruch C. 1999: Effect of L-3, 4-dihydroxyphenylalanine, ornithine and $\gamma$-aminobutyric acid on winter wheat resistance to grain aphid. J. Appl. Entomol. 123: 285-288.

FeENy P.P. 1976: Plant apparency and chemical defense. Rec. Adv. Phytochem. 10: 1-40.

HE Y.Z., WANG Q.Y. \& YANG X.D. 1996: Influences of different growing stages and organs of wheat on the first generation of Helicoverpa armigera (Hubner). J. Agric. Univ. Heibei 19(2): $31-35$.

Hedin P.A., Jenkins J.N. \& Parrott W.L. 1992: Evaluation of flavonoids in Gossypium arboreum (L.) cottons as potential source of resistance to tobacco budworm. J. Chem. Ecol. 18: $105-114$.

Homchan P., Direksri P. \& Rojanavongse V. 1985: Selection of cotton resistance to Heliothis armigera Hubner. http://202.112.175.7:8590/webspirs/doLS.ws?ss=Bankok+in+ SO (abstracts in English).

KaZemi M.H. \& van EMden H.F. 1992: Partial antiibiosis to Rhopalosiphum padi in wheat and some phytochemical correlations. Ann. Appl. Biol. 121: 1-9.
Manuwoto S. \& Scriber J.M. 1982: Consumption and utilization of three maize genotypes by the southern armyworm. $J$. Econ. Entomol. 75: 163-167.

Manuwoto S. \& Scriber M. 1985: Consumption and utilization of experimentally altered corn by southern armyworm: iron, nitrogen, and cyclic hydroxamates. J. Chem. Ecol. 11: 1469-1483.

Meisner J.S., Martin M.M. \& Bernays E.A. 1987: Failure of tannic acid to inhibit digestion or reduce digestibility of plant protein in gut fluids of insect herbivores: implications for theories of plant defense. J. Chem. Ecol. 13: 605-621.

Nicol D., Copaja S.V., Wratten S.D. \& Niemeyer H.M. 1992: A screen of worldwide wheat cultivars for hydroxamic acid levels and aphid antixenosis. Ann. Appl. Biol. 121: 11-18.

Ortego F., Ruiz M. \& CAStañera P. 1998: Effect of DiMBOA on growth and digestive physiology of Sesamia nonagrioides (Lepidoptera: Noctuidae) larvae. J. Insect Physiol. 44: 95-101.

Thackray D.J., Wratten S.D., Edwards P.J. \& Niemeyer H.M. 1990: Resistance to the aphid Sitobion avenae and Rhopalosiphum padi in gramineae in relation to hydroxamic acid levels. Ann. Appl. Biol. 116: 573-582.

SuPRADA S.N.P. 1989: Effects of some cotton-plant substances in artificial diet on the growth and development of the american bollworm, Heliothis armigera (Hubner). http://202.112.175.7:8590/webspirs/doLS.ws?ss=Bankok+in+ SO (abstracts in English).

WALDBAUER G.P. 1968: The consumption and utilization of food by insects. Adv. Insect Physiol. 5: 229-288.

WANG C.Z. 1997: Effect of gossypol and tannic acid on the growth and digestion physiology of cotton bollworm larvae. Acta Phytophyl. Sin. 24(1): 13-18.

WANG C.Z., ZHA L.W. \& YANG Q.H. 1997a: Research on the relationship between larval feeding behavior of cotton bollworm and distribution of harmful allelochemicals in cotton. Acta Entomol. Sin. (Suppl.) 40: 55-60.

Wang Y.B., Lu W.Y., Wang C.H., Sun Y.M. \& Liang C.Y. 1997b: Study on the population situation and harm of cotton bollworm to wheat. J. Henan Voc.-Techn. Teach. Coll. 25(3): $8-11$.

XIA J.Y., MA Y. \& WANG C.Y. 1997: Effects of different host plants on development and reproduction of the cotton bollworm. Acta Phytophyl. Sin. 24: 275-376.

ZuÑIga G.E., Salgado M.S. \& Corcuera L.J. 1985: Role of an indole alkaloid in the resistance of barley seedlings to aphids. Phytochemistry 24: 945-947.

Received November 22, 2004; revised April 1, 2005; accepted October 31, 2005 